\title{
BMJ Open Are dietary patterns differently associated with differentiated levels of mental health problems? Results from a large cross-sectional study among Iranian manufacturing employees
}

\author{
Zahra Heidari, ${ }^{1}$ Awat Feizi, ${ }^{1,2}$ Hamidreza Roohafza, ${ }^{2}$ Katayoun Rabiei, ${ }^{3}$ \\ Nizal Sarrafzadegan ${ }^{3}$
}

To cite: Heidari Z, Feizi A, Roohafza $\mathrm{H}$, et al. Are dietary patterns differently associated with differentiated levels of mental health problems? Results from a large cross-sectional study among Iranian manufacturing employees. BMJ Open 2019;9:e020083. doi:10.1136/ bmjopen-2017-020083

- Prepublication history for this paper is available online. To view these files, please visit the journal online (http://dx.doi. org/10.1136/bmjopen-2017020083).

Received 12 0ctober 2017 Revised 27 July 2018 Accepted 31 October 2018

Check for updates

(c) Author(s) (or their employer(s)) 2019. Re-use permitted under CC BY-NC. No commercial re-use. See rights and permissions. Published by BMJ.

For numbered affiliations see end of article.

Correspondence to

Dr Awat Feizi;

awat_feiz@hlth.mui.ac.ir

\section{ABSTRACT}

Objectives The present study aimed to classify participants based on mental health problems profile and to evaluate its relationship with dietary patterns among Iranian manufacturing employees.

Design Observational study with a cross-sectional design. Setting This study was conducted in Esfahan Steel Company, one of the biggest Iranian industrial manufacturing companies. Participants Complete data on 2942 manufacturing employees, with a mean (SD) age of 36.68 (7.31) years, were analysed.

Outcome measures Hospital Anxiety and Depression Scale(HADA) and General Health Questionnaire (GHQ-12) were used to evaluate anxiety and depression and psychological distress, respectively.

Results Three major dietary patterns, namely 'western', 'healthy' and 'traditional', were extracted using factor analysis. A two-class, one-factor structure was identified from study participants in terms of mental health problems profile based on the factor mixture model. Two identified classes were labelled as 'low mental health problems' (2683 manufacturing employees, 91.2\%) and 'high mental health problems' (259 individuals, 8.8\%). After adjusting for the impact of potential confounders, manufacturing employees in the highest tertile of healthy dietary pattern had lower odds of being in the high mental health problems profile class $(\mathrm{OR}=0.67,95 \% \mathrm{Cl} 0.49$ to 0.92). In contrast, greater adherence to Western and traditional dietary patterns was associated with increased odds of being in the high mental health problems class $(\mathrm{OR}=1.66,95 \% \mathrm{Cl}$ : 1.18 to 2.35 and $\mathrm{OR}=1.52,95 \% \mathrm{Cl}: 1.10$ to 2.11 , respectively). Conclusions Our study provided informative pathways on the association of dietary patterns and mental health among manufacturing employees. The findings can be used by workplace health promotion policymakers in improving mental health in such study population. Interventional and prospective studies that investigate the effects of change in dietary patterns on the mental health of manufacturing employees are suggested.

\section{BACKGROUND}

Mental health problems showed increasing prevalence worldwide and account for $30 \%$

\section{Strengths and limitations of this study}

- This is the first study that evaluated the underlying structure of mental health and that investigated its association with major dietary patterns in a large sample of Iranian industrial manufacturing employees using a comprehensive and advanced statistical method, that is, a multilevel factor mixture model.

- Due to the cross-sectional design of the study, we cannot infer cause-effect associations from the findings.

- All the information used in the present study was gathered by self-administered questionnaires, which might lead to misclassification of participants.

- In factor analysis, selecting the number of factors, the rotation method and labelling the factors are subjective decisions, and this method is not optimum for discrete non-negative data such as count variables.

- The Short-Form Food Frequency Questionnaire used in this study is based on the frequency of consumed food items and groups, not values, and accordingly it does not provide information and data on the values of nutrients and energy intake; in addition, it does not include food items consumed in the form of dietary supplements.

of the global non-fatal disease burden. ${ }^{12}$ According to a report by WHO, between 1990 and 2013, the number of people affected by depression and/or anxiety increased about $50 \%$, from 416 million to 615 million. ${ }^{3}$ In Iran, the prevalence of mental health problems increased from $11 \%$ in 1963 to $34.2 \%$ in $2007 .{ }^{4}$ The incidence of mental health problems varies according to the target population and geographical regions, ${ }^{5}$ and these problems have significant impact on health with major social and economic consequences in all countries over the world. ${ }^{2}$ 
The aetiology of mental health problems is complex and multifactorial, involving interactions between genetic and environmental factors. ${ }^{6}$ Diet and nutrition are related to inflammation, oxidative processes, and brain plasticity and function; all of these factors are potentially involved in mental health. ${ }^{89}$ Previous research on the association between diet and mental health has focused primarily on individual nutrients, such as folate, vitamin $\mathrm{B}_{6}$, vitamin $\mathrm{B}_{12}$ and fatty acids. ${ }^{10-14}$ However, because nutrients and foods are consumed in a combined way, investigation of individual foods or nutrients may provide an incomplete picture of the association between diet and mental health. ${ }^{915}$ In recent years, studying dietary patterns with a global perspective has been suggested as a more comprehensive approach than studying individual foods or nutrients. ${ }^{9}$ There are a few studies on the relationship between dietary patterns and mental health. ${ }^{8}{ }^{915-20}$ A study on 3486 employees in London showed that a whole food dietary pattern has protective effect against depression and a processed food dietary pattern is associated with an increased odds of depression. ${ }^{17}$

It seems that the relationship between dietary patterns and mental health particularly is complex and may depend on the studied population. Manufacturing employees are exposed to high degrees of job stress; however, little studies have elaborated the contribution of effective factors, particularly modifiable, protective or risk factors, of mental problems so far among this specific population. In the current study, using a factor mixture model (FMM $)^{21}$ as an advanced statistical method, a combined variable as a latent construct (mental health profile) was extracted based on three indicators, that is, depression, anxiety and psychological distress; with the high incidence of comorbid or co-occurrence of mental health problems, such a combined variable will provide a comprehensive and integrative picture of mental health. ${ }^{22}$ Therefore, the current study aimed to classify the study population (ie, a relatively large sample of Iranian manufacturing employees) into subgroups representing different levels of mental health profile. Moreover, an extended version of FMM was used to assess the relationship between major dietary patterns (as latent predictors) and mental health profile considering the hierarchical structure of our data (ie, manufacturing employees are nested in different occupational settings as a higher level). We hypothesised that the dietary patterns are differently associated with differentiated levels of mental health problems profile, and more specifically Western and traditional dietary patterns have significant positive relationships with higher mental health problems. Also we postulated that a healthy dietary pattern will have a significant protective role against higher mental health problems.

\section{MATERIALS AND METHODS}

\section{Study design and participants}

This cross-sectional study was conducted in 2014 among 16000 formal and contractual employees of Esfahan Steel Company (ESCO), one of the biggest Iranian manufacturing companies. The sample size was 3500 , which determined an accurate and reliable estimate of the prevalence of mental health problems of about 0.1 , considering a type 1 error rate of 0.05 and a sampling error rate of 0.01 . The inclusion criteria were work experience for at least 1 year and enthusiasm in participation. The participants who did not answer to a large fraction of questions (more than $10 \%$ of questionnaires' pages, included 37 employees) were excluded. Multistage random cluster sampling along with stratified sampling based on managerial departments was used for participant selection. The clusters were the seven main management departments and their subsidiary sections, and the strata were the job categories of employees in ESCO. Sample sizes in the clusters and strata were proportional to size. Due to the random nature of sampling, as well as the low number of female employees $(n=800)$, we included 260 willing women intentionally to reach a sufficient sample size of women. Information on sociodemographic, job-related as well as lifestyle and mental health variables was collected through structured and validated self-administrated (pen/paper) questionnaires. Questionnaire administration and data collection were conducted for 6 months at the company, and research assistants guided the participants with regard to possible ambiguities. Simultaneously the process was monitored rigorously by study coordinators over the study period. In this period, 3063 employees returned completed questionnaires (response rate: 87\%). Informed consent was obtained from all participants before the investigation. In the current study, 2942 manufacturing employees with complete data contributed to the analysis.

\section{Procedures and assessment of variables}

Psychological distress

To assess the psychological distress of the manufacturing employees, an Iranian validated version of the General Health Questionnaire (GHQ-12) was used. ${ }^{23}{ }^{24}$ It is a self-administered questionnaire that asks whether the participant has experienced psychological, social and somatic symptoms or behaviours recently. ${ }^{2324}$ It is therefore sensitive to shortterm psychological distress but not to long-standing attributes of the participant. Each item of the questionnaire has a 4-point scale (less than usual, no more than usual, rather more than usual or much more than usual). In the current study, Goldberg's original scoring method (bimodal [0-0-11]) was used, which gives respondent scores that range from 0 to 12 points. ${ }^{24}$ The GHQ-12 scores are divided into normal $(0-3)$ and high $(\geq 4)$, as recommended in the GHQ-12 manual. ${ }^{24}$ Therefore, in the current study, a cut-off score of 4 or above indicates a high probability of a person being at a clinically significant level of distress. Cronbach's alpha coefficient was used to assess internal consistency and was found to be $0.87 .{ }^{23}$

\section{Hospital Anxiety and Depression Scale}

The Iranian validated version of the Hospital Anxiety and Depression Scale (HADS) was used to assess anxiety and depression of the manufacturing employees. ${ }^{25}$ It consists of two separate subscales, HADS-A and HADS-D, which 
evaluate anxiety and depression, respectively. HADS consists of 14 items, 7 of which relate to anxiety and 7 to depression. Each item includes a 4-point Likert scale ranging from 0 (not present) to 3 (considerable). Therefore, for each subscale, the maximum score is 21. In the current study, scores of $0-7$ on either subscale were defined as 'normal', scores of $8-10$ represent 'borderline', and scores of 11 or more were considered a significant 'case' of psychological morbidity. Internal consistency as measured by Cronbach's alpha coefficient has been found to be $0.78 .^{26}$

\section{Dietary assessment}

A self-administered Food Frequency Questionnaire (FFQ-Short Form) was used to assess the dietary data of the manufacturing employees. ${ }^{27}$ The FFQ consists of a list of food items and food groups commonly consumed by Iranians, including grains (bread, rice, different types of 'cakes, pastry and biscuits', potato, spaghetti, soya, beans), dairy products (low-fat milk, low-fat yoghourt, high-fat milk, high-fat yoghourt, butter, cream, cheese, yoghourt-based beverage), fruits, vegetables, oil (liquid oil, hydrogenated oil), meat ('liver-lung', processed meat, poultry, red meat, fish), mixed dishes (canned food, fast foods, fried foods and restaurant foods, organ meat), and miscellaneous food items and beverages (including carbonated drinks, all kinds of jam, fresh fruit juice, all kinds of seeds, fruit juice, mayonnaise, egg, nuts, garlic).

First, participants were asked to select the 'yes' option if they consumed the proposed food items. Then, those who selected 'yes' were asked to indicate the period of food consumption as daily, weekly, monthly or yearly in an open-ended format. Also, based on the selected option for period, participants were asked to report the frequency of food consumption as the number of 'times' each a day or week or month or year. Finally, the reported frequency of each food item was then converted into a weekly consumption ('times' of consumption in a week). Participants could also select seldom/never option if they never consumed the proposed food items. Seldom and never were calculated as 'zero'. In the current study, some FFQ items were combined and a 38-item FFQ was finally used to collect dietary data. The FFQ Short Form or a 48-item version was validated in the Iranian population. The reproducibility of the FFQ as assessed by intraclass correlation has been found to be between 0.47 and 0.69 in different food groups. ${ }^{27}$ It is necessary to mention that daily energy and nutrient intake of each participant was not calculated using this instrument.

\section{Assessment of other variables}

Self-administered standard questionnaires were distributed to obtain demographic, lifestyle and job-related characteristics. Demographic characteristics included age (year), gender, marital status (single/married), educational level ( $0-5$ years, $6-12$ years and $>12$ years) and family size. Lifestyle characteristics included weight $(\mathrm{kg})$, height $(\mathrm{m})$, sleep duration (hours), smoking status (non-smoker, former smoker and current smoker and the number of smoked cigarettes) and physical activity (hours per week). In the current study, the short form of the International Physical Activity Questionnaire (IPAQ$\mathrm{SF}$ ) was used to assess physical activity. ${ }^{28}$ In the IPAQ-SF, which is a validated instrument (Cronbach's alpha of 0.87 ), participants were asked about both the frequency (days) and the duration (the average time in minutes) of their physical activities. The sum of vigorous, moderate and walking physical activity scores was considered as the total physical activity score for each participant. ${ }^{28}$

Job-related characteristics included the type of occupation, shift work (daily/shifty), second job (yes/no) and the effort to reward ratio (ER ratio, 0-2 scores). The Persian validated version of the Effort-Reward Imbalance (ERI) questionnaire, which has three scales, namely effort (6 items), reward (11 items) and overcommitment (6 items), was used to measure the ER ratio. In the effort and reward scales, participants were asked to answer to statements which imply a typical experience in their work situation on a 5-point Likert scale (1: no respective stressful experience to 5 : very high stressful experience). A ratio between the two scales of effort and reward was calculated to define ERI. Participants who had an ER ratio score of 1.0 or higher are considered to experience ERI. The Cronbach's alpha coefficients of the Persian version of ERI for effort, reward and overcommitment subscales were $0.61,0.85$ and 0.67 , respectively. ${ }^{29}$

\section{Patient and public involvement}

Through multistage random cluster sampling, the manufacturing employees were selected in the ESCO. After obtaining informed consent from participants, questionnaire administration and data collection were conducted at the company. No specific patient group was included in the study.

\section{Statistical analysis}

Dietary patterns were extracted using exploratory factor analysis based on a principal component extraction approach on the 38 food items and food groups. The orthogonal varimax rotation procedure was used to find the interpretable factors. Factors were retained for further analysis based on eigenvalues on the scree plot and their natural interpretation. In this study, we retained factors with eigenvalues $>2$ as this cut-off could result in more interpretable dietary patterns and explain sufficient amounts of overall variation. We found three interpretable dietary patterns and they were labelled based on the loaded items in each factor and of the earlier literature. The dietary pattern scores were calculated by summing the intake of food items weighted by their factor loadings, and each participant received a score for each identified pattern. We categorised participants by tertiles of dietary pattern scores.

To analyse the latent structure of mental health and its association with dietary patterns, FMM was applied. FMM is a hybrid model that allows the underlying structure to 
be simultaneously dimensional and categorical. ${ }^{21}$ This structure is considered categorical because FMM classifies the individuals into subgroups (ie, latent classes), and it is also considered dimensional because it captures the heterogeneity within groups using continuous latent variables by examining the relations among the observed indicators. ${ }^{21}$ In addition, we also used some extensions of FMM to include a set of explanatory variables in the main structure of the model, as well as taking into account the hierarchical structure of the data. ${ }^{21} 30$

The process of fitting FMM was as follows: In a unified modelling framework, a latent variable (ie, mental health problems profile) was extracted from combining the scores of three mental health problems (depression, anxiety and psychological distress), and through a search process to find the best classification (ie, lower values of Bayesian Information Criterion [BIC] and higher values of entropy index) of study participants based on their mental health problems profile, FMMs without predictors with two to three classes were fitted; an FMM model with two latent classes (ie, 'low mental health problems' and 'high mental health problems' classes) was found to be best based on both interpretability and statistical fitting criteria. Then, we fitted a multilevel factor mixture model (MFMM) with one latent factor (mental health profile) and two latent classes along with covariates. The assumption of independent observations is inadequate with hierarchical or multilevel data (ie, when the indicators are measured on individuals [lower level units] which are nested within groups [higher level units] $).{ }^{30}$ In such situations, it is more appropriate to use multilevel techniques. ${ }^{30}$ We included the 'type of occupation' of the manufacturing employees as clusters (higher level units) in the MFMM model because work characteristics are important determinants of mental health. In each subgroup or class, the association between the latent factor (mental health profile as dependent variable) and major dietary patterns (as predictors) was evaluated, while adjustment was made for the impact of potential confounding variables.

After finalising the MFMM fitting, binary logistic regression was used to model the relation of dietary patterns as independent variables, adjusted by demographic variables (age, gender, marital status, educational level and family size), lifestyle variables (sleep duration, physical activity, body mass index [BMI] and smoking) and job-related characteristics (type of occupation, shift work, second job and the effort-reward ratio [ER ratio]), with the extracted classes of mental health as the response variable. In the analyses, the first tertile of dietary pattern scores was considered as the reference category. To assess the overall trend of ORs across tertiles of dietary pattern scores, we treated the tertiles as an ordinal variable in the analyses.

Continuous and categorical variables were expressed as mean (SD) or median (IQR) as appropriate and frequency (percentage), respectively. Normality of continuous data was evaluated using Kolmogrov-Smirnov and $\mathrm{Q}-\mathrm{Q}$ plot. Positively skewed data were subjected to logarithmic transformation. One-way analysis of variance and $\chi^{2}$ tests were used to compare the transformed variables and the prevalence of mental health problems across tertiles of dietary patterns, respectively. We used independent sample Student's t-test and $\chi^{2}$ test, where appropriate, to compare the study participants' characteristics between classes of mental health problems profile.

\section{RESULTS}

Overall, 2942 manufacturing employees contributed to the current study. The mean (SD) age was $36.68(7.32)$ years. They consisted of 2689 (91.4\%) men; 2647 (90\%) were married and $885(30.1 \%)$ had a college education. Anxiety, depression and psychological distress were identified in $8.9 \%, 6.7 \%$ and $4.6 \%$ of the participants, respectively. The mean (SD) scores of anxiety, depression and psychological distress were 2.23 (2.93), 2.17 (2.58) and 0.62 (1.35), respectively. About $2.2 \%$ of individuals were underweight (BMI <18.5), $43.9 \%$ were overweight (BMI 25-30) and $11.7 \%$ were obese (BMI $>30$ ). Of the participants, $29.1 \%$ were smokers. Of the manufacturing employees, $54.8 \%$ were working in shifts and $9.3 \%$ had a second job. About $16 \%$ of employees earned less than $\$ 125$ a month, $52 \%$ between $\$ 125$ and $\$ 200,22 \%$ between $\$ 200$ and $\$ 300$, and the rest earned more than $\$ 300$ in a month.

\section{Extraction of major dietary patterns using factor analysis}

We identified three major dietary patterns based on 38 food items/groups: (1) a 'western' dietary pattern, characterised by high intake of butter, cream, 'liver, lung', organ meat, processed meat, spaghetti, carbonated drinks, all kinds of jam, 'pastry, biscuits, cookies, chocolates', fresh fruit juice, all kinds of seeds, fruit juice, canned food, fast foods, mayonnaise and egg; (2) a 'healthy' dietary pattern, which was high in liquid oil, cheese, low-fat milk, low-fat yoghourt, yoghourt-based beverage, fish, fruits, vegetables, nuts, soya, garlic and beans; and (3) a 'traditional' dietary pattern, which was highly loaded with hydrogenated oil, high-fat milk, high-fat yoghourt, red meat, poultry, all kinds of bread, rice, potato, fried foods and restaurant foods; they accounted for $7.8 \%, 6.3 \%$ and $6.1 \%$ of the whole variance in dietary intake, respectively (table 1).

\section{Mental health variables across tertiles of dietary pattern scores}

According to table 2, the mean scores of depression, anxiety and psychological distress were significantly different across tertiles of different dietary patterns $(p<0.05)$. Compared with those in the lowest tertile of the Western and traditional dietary patterns, individuals in the top tertile had significantly higher scores of depression, anxiety and psychological distress $(p<0.05)$. In contrast, participants in the top tertile of the healthy dietary pattern had significantly lower scores in mental health problems $(\mathrm{p}<0.05)$. 
Table 1 Factor loading matrix for the major dietary patterns identified among the sample of Iranian manufacturing employees

\begin{tabular}{|c|c|c|c|}
\hline \multirow[b]{2}{*}{ Food item/group } & \multicolumn{3}{|c|}{ Dietary pattern } \\
\hline & Western & Healthy & Traditional \\
\hline Butter & 0.368 & & \\
\hline Cream & 0.434 & & \\
\hline Liver, lung & 0.401 & & \\
\hline Organ meat & 0.307 & & \\
\hline Processed meat & 0.546 & & \\
\hline Spaghetti & 0.349 & & \\
\hline Carbonated drinks & 0.536 & & \\
\hline All kinds of jam & 0.387 & & \\
\hline $\begin{array}{l}\text { Pastry, biscuits, } \\
\text { cookies, chocolates }\end{array}$ & 0.375 & & \\
\hline Fresh fruit juice & 0.324 & & \\
\hline All kinds of seeds & 0.35 & & \\
\hline Fruit juice & 0.476 & & \\
\hline Canned food & 0.333 & & \\
\hline Fast foods & 0.564 & & \\
\hline Mayonnaise & 0.384 & & \\
\hline Egg & 0.289 & & \\
\hline Liquid oil & & 0.236 & \\
\hline Cheese & & 0.199 & \\
\hline Low-fat milk & & 0.354 & \\
\hline Low-fat yoghourt & & 0.46 & \\
\hline $\begin{array}{l}\text { Yoghourt-based } \\
\text { beverage }\end{array}$ & & 0.438 & \\
\hline Fish & & 0.368 & \\
\hline Fruits & & 0.426 & \\
\hline Vegetables & & 0.503 & \\
\hline Nuts & & 0.437 & \\
\hline Soya & & 0.282 & \\
\hline Garlic & & 0.374 & \\
\hline Beans & & 0.399 & \\
\hline Hydrogenated oil & & & 0.271 \\
\hline High-fat milk & & & 0.396 \\
\hline High-fat yoghourt & & & 0.517 \\
\hline Red meat & & & 0.505 \\
\hline Poultry & & & 0.387 \\
\hline All kinds of bread & & & 0.417 \\
\hline Rice & & & 0.459 \\
\hline Potato & & & 0.432 \\
\hline Fried foods & & & 0.39 \\
\hline Restaurant foods & & & 0.113 \\
\hline $\begin{array}{l}\% \text { of variance } \\
\text { explained }\end{array}$ & 7.8 & 6.3 & 6.1 \\
\hline
\end{tabular}

Classifying study participants in terms of mental health problems profile using FMM

The latent structure (mental health problems profile) of the study population in terms of the three mental health problems, that is, depression, anxiety and psychological distress, was recognised using FMM. We observed the highest value of entropy index (0.979) and the lowest BIC (20063.774) for two-class, one-factor solution, suggesting that this model correctly classifies individuals with the highest probability. The two identified classes were labelled as 'high mental health problems' (which included 259 participants, 8.8\%) and 'low mental health problems' (which included 2683 individuals, 91.2\%) because the mean $(\mathrm{SD})$ value of mental health problems profile score was 16.31 (8.18) in the first and 3.94 (4.3) in the second class, indicating higher levels of mental health problems in the first class than the second.

\section{Distribution of demographic, lifestyle, job-related} characteristics, mental health and dietary patterns of manufacturing employees across two extracted classes

According to table 3, the distribution of age, marital status, family size, BMI, smoking, second job, income and ER ratio variables was not significantly different between high and low mental health problems profile classes. The mean sleep duration was significantly lower in high mental health problems profile class than the other class (6.66 hours vs 7.15 hours; $p<0.001$ ). In addition, manufacturing employees who belong to the high mental health problems class were significantly less physically active ( 7.33 hours in a week vs 9.81 hours in a week; $\mathrm{p}<0.001$ ). There was a significant difference between the two classes in terms of shift work's distribution $(45.9 \%$ vs $55.6 \%$ for high and low mental health problems classes; $p=0.003$ ) (table 3).

\section{How dietary patterns predict participants' mental health class} membership

Crude and multivariable adjusted ORs for the association of mental health problems classes and dietary patterns are provided in table 4 . Individuals in the third tertile of the Western dietary pattern had a higher chance of being in the high mental health problems class in all crude and adjusted models (OR=1.66, 95\% CI:1.18 to 2.35 for the last model). In contrast, individuals in the third tertile of the healthy dietary pattern tended to have lower odds of membership in the high mental health problems profile class ( $\mathrm{OR}=0.67,95 \%$ CI:0.49 to 0.92$)$. Also, participants in the third tertile of the traditional dietary pattern had higher chance of being in the high mental health problems profile class in all crude and adjusted models (OR=1.52, 95\% CI:1.10 to 2.11 for the last model).

\section{Association of dietary patterns with profile of mental health problems using factor mixture modelling}

Table 5 presents the results of the MFMM in different models, for evaluating the association between dietary patterns and mental health problems profile scores in two extracted classes. The regression coefficients suggest positive associations between Western and traditional dietary patterns and scores of mental health problems 


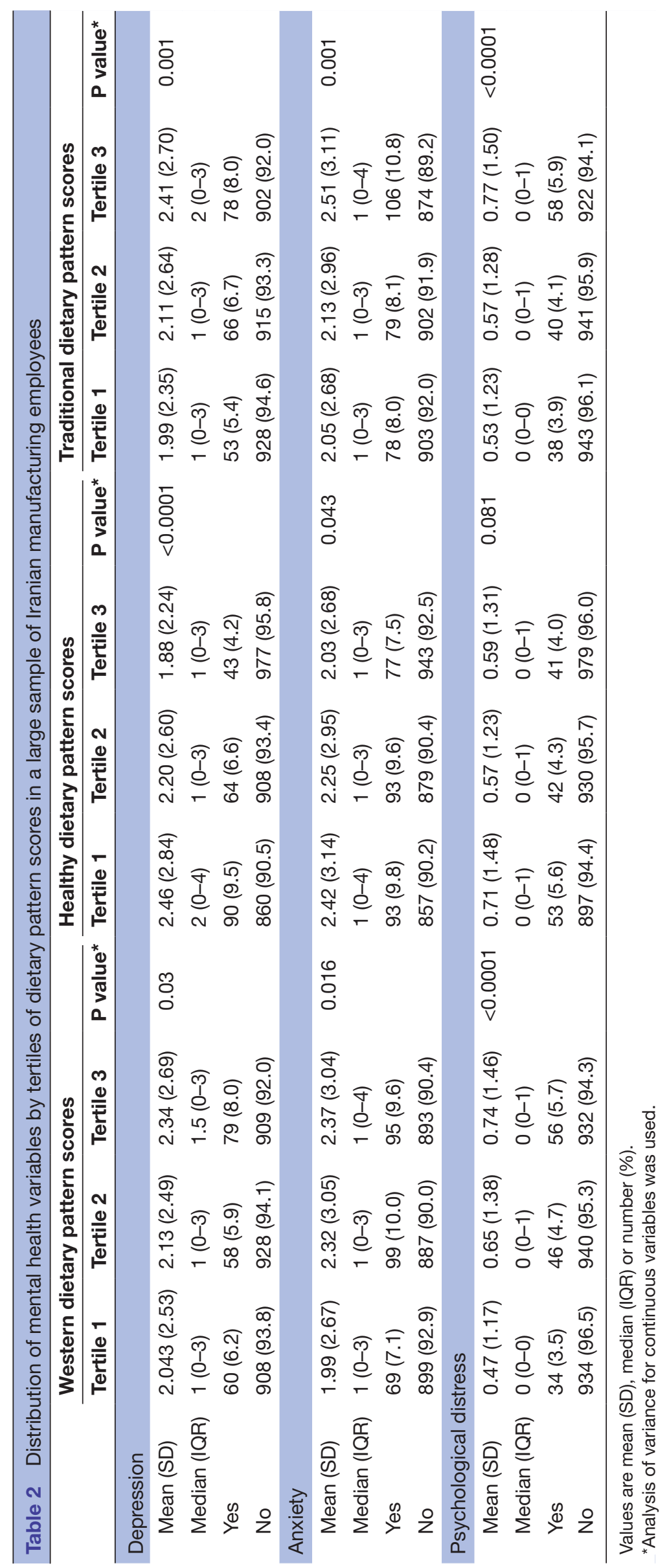


Table 3 Distribution of demographic, lifestyle, job-related characteristics, mental health and dietary patterns of study participants across two extracted latent classes of mental health problems

\begin{tabular}{|c|c|c|c|}
\hline & $\begin{array}{l}\text { High mental } \\
\text { health } \\
\text { problems } \\
\text { class }(n=259)\end{array}$ & $\begin{array}{l}\text { Low mental } \\
\text { health } \\
\text { problems class } \\
(\mathrm{n}=2683)\end{array}$ & P value* \\
\hline \multicolumn{4}{|c|}{ Demographic characteristics } \\
\hline Age (years) & $36.53(7.12)$ & $36.69(7.34)$ & 0.733 \\
\hline Male & $228(88.0)$ & $2461(91.7)$ & 0.043 \\
\hline \multicolumn{2}{|l|}{ Marital status } & & 0.191 \\
\hline Married & $227(87.6)$ & $2420(90.2)$ & \\
\hline \multicolumn{2}{|l|}{ Educational level } & & 0.012 \\
\hline $6-12$ years & $143(55.2)$ & $1688(62.9)$ & \\
\hline$>12$ years & $98(37.8)$ & 787 (29.3) & \\
\hline \multirow[t]{2}{*}{ Family size } & $4(3-4)$ & $4(3-4)$ & 0.268 \\
\hline & $3.67(1.18)$ & $3.59(1.09)$ & \\
\hline \multicolumn{4}{|l|}{ Lifestyle characteristics } \\
\hline \multirow[t]{2}{*}{ Sleep duration (hours) } & $7(6-8)$ & $7(6-8)$ & $<0.001$ \\
\hline & $6.66(1.29)$ & $7.15(1.15)$ & \\
\hline \multirow{2}{*}{$\begin{array}{l}\text { Physical activity } \\
\text { (score) }\end{array}$} & $3(1.17-7.25)$ & $4.5(2-11)$ & $<0.001$ \\
\hline & $7.33(11.83)$ & $9.81(14.7)$ & \\
\hline \multicolumn{2}{|l|}{ Body mass index } & & 0.242 \\
\hline $\begin{array}{l}\text { Underweight } \\
(<18.5)\end{array}$ & $6(2.3)$ & $58(2.2)$ & \\
\hline Overweight (25-30) & $122(47.1)$ & $1171(43.6)$ & \\
\hline Obese $(>30)$ & $20(7.7)$ & $324(12.1)$ & \\
\hline \multicolumn{2}{|l|}{ Smoking } & & 0.124 \\
\hline Yes & $86(33.2)$ & $769(28.7)$ & \\
\hline \multicolumn{4}{|l|}{ Job-related characteristics } \\
\hline \multicolumn{2}{|l|}{ Shift work } & & 0.003 \\
\hline Yes & $119(45.9)$ & $1493(55.6)$ & \\
\hline \multicolumn{2}{|l|}{ Second job } & & 0.533 \\
\hline Yes & $27(10.4)$ & $248(9.2)$ & \\
\hline ER ratio & $0.65(0.27)$ & $0.67(0.22)$ & 0.193 \\
\hline \multicolumn{2}{|l|}{ Income } & & 0.072 \\
\hline$<\$ 125$ & $43(16.6)$ & $420(15.7)$ & \\
\hline$\$ 125-\$ 200$ & $115(44.4)$ & $1397(52.2)$ & \\
\hline$\$ 200-\$ 300$ & $71(27.4)$ & $573(21.4)$ & \\
\hline$>\$ 300$ & $30(11.6)$ & $284(10.6)$ & \\
\hline \multicolumn{4}{|c|}{ Mental health characteristics } \\
\hline Anxiety (score) & $6.36(4.45)$ & $1.83(2.39)$ & $<0.0001$ \\
\hline Depression (score) & $5.69(3.71)$ & $1.83(2.15)$ & $<0.0001$ \\
\hline $\begin{array}{l}\text { Psychological } \\
\text { distress (score) }\end{array}$ & $4.25(1.62)$ & $0.27(0.58)$ & $<0.0001$ \\
\hline \multicolumn{4}{|l|}{ Dietary patterns } \\
\hline \multicolumn{2}{|c|}{ Western dietary pattern scores } & & 0.004 \\
\hline Tertile 1 & $63(24.3)$ & $905(33.7)$ & \\
\hline Tertile 2 & $95(36.7)$ & $891(33.2)$ & \\
\hline Tertile 3 & $101(39.0)$ & $887(33.1)$ & \\
\hline
\end{tabular}

Continued
Table 3 Continued

\begin{tabular}{cclc}
\hline & $\begin{array}{l}\text { High mental } \\
\text { health } \\
\text { problems } \\
\text { class }(\mathbf{n}=\mathbf{2 5 9})\end{array}$ & $\begin{array}{l}\text { Low mental } \\
\text { health } \\
\text { problems class } \\
(\mathbf{n = 2 6 8 3})\end{array}$ & P value* \\
\hline Healthy dietary pattern scores & & 0.004 \\
Tertile 1 & $105(40.5)$ & $845(31.5)$ & \\
Tertile 2 & $79(30.5)$ & $893(33.3)$ & \\
Tertile 3 & $75(29.0)$ & $945(35.2)$ & \\
Traditional dietary pattern scores & & \\
Tertile 1 & $75(29.0)$ & $906(33.8)$ & \\
Tertile 2 & $81(31.3)$ & $900(33.5)$ & \\
Tertile 3 & $103(39.8)$ & $877(32.7)$ & \\
\hline
\end{tabular}

Values are mean (SD) or median (IQR) and others are number (\%). ${ }^{*} \mathrm{P}$ values from independent samples t-test for continuous data and from Pearson $\chi^{2}$ for categorical data.

$\mathrm{ER}$, ratio, effort to reward ratio.

profile in the crude and adjusted models. In addition, the regression coefficients present negative associations between healthy dietary patterns and scores of mental health problems profile in the adjusted models. However, the obtained results were only statistically significant for traditional and healthy dietary patterns in the low mental health problems profile class $(\mathrm{p}<0.05)$. For instance, when adjustments were made for demographic, lifestyle and job-related characteristics (model IV), the regression coefficients for healthy dietary pattern were -0.771 and $-0.341(\mathrm{p}<0.05)$ for the high and low mental health problems profile classes, respectively. Also, in model IV, the regression coefficients for the association of traditional dietary pattern and mental health profile were 0.616 and $0.567(\mathrm{p}<0.001)$ for the high and low mental health problems profile classes, respectively.

\section{DISCUSSION}

In this cross-sectional study, an advanced statistical method, that is, FMM, was introduced to evaluate the latent structure of mental health problems of manufacturing employees. In the current study, depression, anxiety and psychological distress were considered to evaluate the latent structure of mental health. Our study also provided a more comprehensive picture of the association between major dietary patterns and mental health problems. We considered a hierarchical or multilevel structure for our data by including the 'type of occupation' of manufacturing employees as higher level units in the FMM model, because work characteristics are important determinants of mental health. ${ }^{31} 32$ The results of our study suggested two subgroups of manufacturing employees: individuals with elevated mental health problems $(8.8 \%$ of the sample) and individuals with low levels of mental health problems (91.2\%).

We found an inverse association between a healthy dietary pattern and mental health problems profile. These 


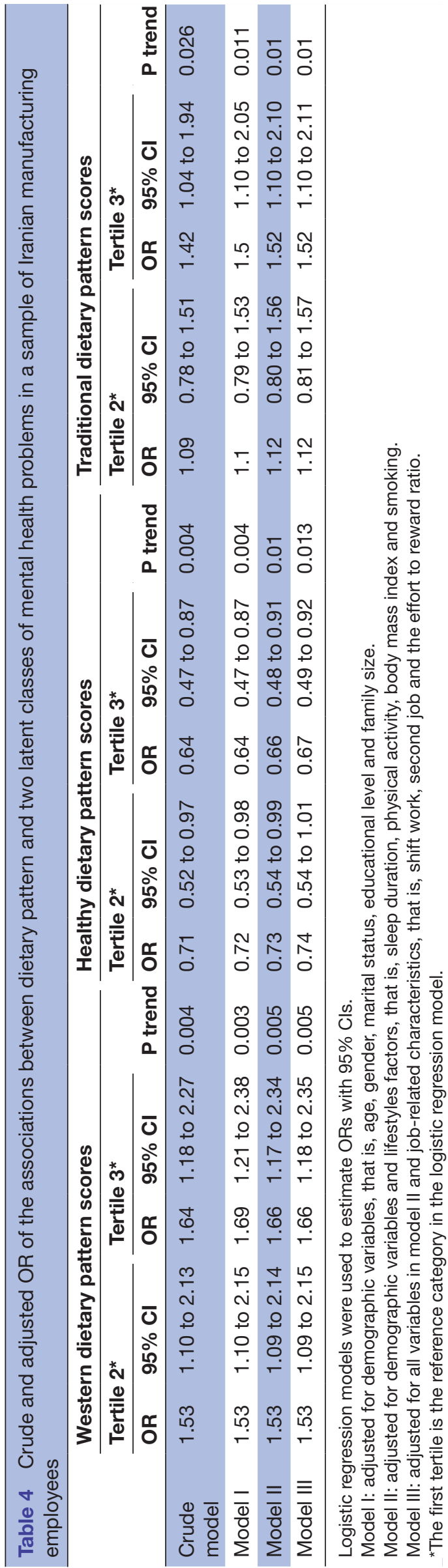

findings are in line with some previous studies. ${ }^{8} 151718$ However, these studies have examined mental health characteristics, such as depression and anxiety, separately, but in the current study we examined an integrated profile of mental health by combining these problems. In line with our findings, the study of Akbaraly et $\mathrm{al}^{17}$ showed that 'whole food' dietary pattern, loaded with high intake of vegetables, fruits and fish, has a protective role against depression. In Hosseinzadeh et $a l \mathrm{~s}^{\mathrm{s}}{ }^{18}$ study on 3846 Iranian adults, a lacto-vegetarian dietary pattern, highly loaded with more intake of non-flatulent vegetables, fruits and low-fat dairy products, was protectively associated with depression in women. In Jacka $e t a l \mathrm{~s}^{8}$ study, women with higher score on a healthy dietary pattern were less likely to be depressed or anxious.

We found that the traditional dietary pattern is positively associated with the higher scores in mental health problems profile. In Hosseinzadeh et $a l \mathrm{~s}^{18}$ study, 'traditional' dietary pattern, loaded with vegetable oil, meat, salt and organ meat, was associated with increased odds of anxiety and depression in women. However, in contrast to our findings, in the two Australian studies, a protective association between traditional dietary pattern and mental health problems was found. ${ }^{815}$ The food content of traditional dietary patterns in the different studies, as well as the interactions of various food items in the dietary patterns, might explain these inconsistencies.

According to logistic regression, we found that the Western dietary pattern tended to be associated with increased odds of membership in the high mental health problems profile class. The results of Akbaraly et $a l^{17}$ study showed that high consumption of 'processed food' dietary pattern, loaded with high intake of sweetened desserts, chocolates, fried food and processed meat, is associated with an increased odds of depression. In Hosseinzadeh et $a l \mathbf{s}^{18}$ study, the Western dietary pattern was associated with increased odds of depression in men and anxiety in normal-weight participants. In Jacka et $a l \mathrm{~s}^{8}$ study, a Western-type diet was associated with increased anxiety in Australian men and women, too.

There are several plausible underlying mechanisms that could explain the association between mental health and dietary intake. Lifestyle in its all domains is strongly associated with physical and mental well-being and finally quality of life, ${ }^{33}$ and nutritional habits in the framework of lifestyle have an essential role. Diet quality or dietary patterns through provision of nutrient profiles with different intake of effective nutrients for inflammation, immune system dysfunction, oxidative stress and biochemistry effectively are linked with mental health. ${ }^{893435} \mathrm{On}$ the other hand, it should be noted that this association could be a mutual pathway in which mental health status affects people's dietary habits and finally nutrient intake and profile. Fruits and vegetables loaded on our healthy dietary pattern are rich in folate and antioxidants, which are potentially associated with decreased inflammation and oxidative stress. ${ }^{36}$ Some studies showed that low levels of folate might increase the risk of depression. ${ }^{17} 37$ 
Table 5 Association of mental health problems profile and dietary patterns in two extracted classes

\begin{tabular}{|c|c|c|c|}
\hline \multicolumn{2}{|c|}{ Dietary pattern } & \multirow{2}{*}{$\begin{array}{l}\begin{array}{l}\text { High mental } \\
\text { health problems } \\
\text { class }(\mathbf{n}=259)\end{array} \\
0.131(0.272)\end{array}$} & \multirow{2}{*}{$\begin{array}{l}\begin{array}{l}\text { Low mental health } \\
\text { problems class } \\
\text { (n=2683) }\end{array} \\
0.076(0.128)\end{array}$} \\
\hline Western & $\begin{array}{l}\text { Crude } \\
\text { model }\end{array}$ & & \\
\hline & Model II & $0.172(0.239)$ & $0.119(0.084)$ \\
\hline & Model III & $0.158(0.204)$ & $0.098(0.082)$ \\
\hline & Model IV & $0.148(0.206)$ & $0.099(0.081)$ \\
\hline \multirow[t]{4}{*}{ Healthy } & $\begin{array}{l}\text { Crude } \\
\text { model }\end{array}$ & $0.002(0.000)$ & $0.177(0.884)$ \\
\hline & Model II & $-0.711(0.859)$ & $-0.339(0.175)^{*}$ \\
\hline & Model III & $-0.772(0.982)$ & $-0.328(0.172)^{*}$ \\
\hline & Model IV & $-0.771(0.890)$ & $-0.341(0.173)^{\star \star}$ \\
\hline \multirow[t]{4}{*}{ Traditional } & $\begin{array}{l}\text { Crude } \\
\text { model }\end{array}$ & $0.384(0.384)$ & $0.378(0.113)^{\star \star *}$ \\
\hline & Model II & $0.631(0.397)$ & $0.550(0.145)^{\star \star \star \star}$ \\
\hline & Model III & $0.547(0.434)$ & $0.565(0.149)^{\star \star \star *}$ \\
\hline & Model IV & $0.616(0.413)$ & $0.567(0.149)^{\star \star \star \star}$ \\
\hline
\end{tabular}

All presented values are regression coefficient and its SE, which resulted from one-factor, two-class factor mixture model solution considering 'type of occupation' as clusters (higher level units).

Crude model: no adjustment was done for confounding variables.

Model II: adjustment was done for demographic variables, that is, age, gender, marital status, educational level and family size.

Model III: adjustment was done for demographic variables and lifestyles factors, that is, sleep duration, physical activity, body mass index and smoking.

Model IV: adjustment was done for all variables in model III and job-related characteristics, that is, shift work, second job and the effort to reward ratio.

${ }^{*} \mathrm{P}<0.1,{ }^{* *} \mathrm{p}<0.05,{ }^{* * *} \mathrm{p}<0.01,{ }^{* * *} \mathrm{p}<0.001$.

On the other hand, the high content of antioxidants in fruits and vegetables could be associated with lower risk of depression. ${ }^{17}$ In addition, a further plausible mechanism includes fish consumption. It seems that high intake of fish, which contains omega-3 fatty acids, can also help brain function and is associated with low incidence of depression. ${ }^{18}$ Omega-3 fatty acids are a major component of neuron membranes and have vascular and anti-inflammatory properties. ${ }^{17}$ It is believed that the increased risk of psychological problems, particularly depression, by Western dietary pattern, which is composed of refined carbohydrates and sugar, is associated with increased levels of inflammatory markers, interleukin- 6 and $\mathrm{C}$ reactive protein, a marker of low-grade inflammation. ${ }^{38}$

Although our study is one of the few studies that evaluated the underlying structure of mental health and that investigated its association with major dietary patterns in a large sample of Iranian manufacturing employees using a comprehensive and advanced statistical method, adjusting the impact of a wide variety of confounders that might affect psychological conditions of employees, its limitations should be taken into account while interpreting the results. First, due to the cross-sectional design of the study, we cannot infer cause-effect associations from the findings. We did not have any data on those participants who refused to participate in our study; therefore, the generalisability of results should be interpreted cautiously. It should also be mentioned that all the information used in the present study was gathered by self-administered questionnaires, which might lead to misclassification of participants. The subjective decisions in factor analysis, such as the number of factors to be extracted, selecting the method of rotation and labelling the factors, should be considered while interpreting the results. In factor analysis, the latent variable and noise are modelled by Gaussian random vectors, ${ }^{39}$ so these methods are not really suitable for non-negative data such as count variables. The short FFQ used in our study is based on the frequency of consumed food items and groups, not values; accordingly, this questionnaire does not provide information and data on the values of nutrients and energy intake. In addition, the instrument used does not include food items consumed in the form of dietary supplements as well as the different types of a food item. Finally, part of the observed relationships in this study may be due to a healthy worker effect.

\section{CONCLUSION}

According to the results of this study, avoidance of traditional and Western dietary patterns and adherence to a healthy dietary pattern can be associated with improvements in the mental health of manufacturing employees. The findings can be used by workplace health promotion policymakers in improving the mental health of such study population. It is recommended that in future studies the effects of changes in dietary patterns on the mental health of manufacturing employees be investigated.

\section{Author affiliations}

${ }^{1}$ Department of Biostatistics and Epidemiology, School of Health, Isfahan University of Medical Sciences, Isfahan, The Islamic Republic of Iran

${ }^{2}$ Isfahan Cardiac Rehabilitation Research Center, Cardiovascular Research Institute, Isfahan University of Medical Sciences, Isfahan, The Islamic Republic of Iran

${ }^{3}$ Isfahan Cardiovascular Research Center, Cardiovascular Research Institute, Isfahan University of Medical Sciences, Isfahan, The Islamic Republic of Iran

Acknowledgements The present article was extracted from a Biostatistics PhD thesis at the School of Health, Isfahan University of Medical Sciences, with project number 394832. We are grateful from all the employees of Esfahan Steel Company who kindly participated in our study.

Contributors HR, KR and NS contributed to the conception and design of the study, and collection and assembly of the data. ZH and AF contributed to statistical analysis and interpretation of the data, and drafting of the manuscript.

Funding The current study was financially supported 'in part' by a grant from the Vice Chancellery for Research and Technology, Isfahan University of Medical Sciences (IUMS).

Competing interests None declared.

Patient consent for publication Obtained. 
Ethics approval The medical research ethics committee of the Isfahan University of Medical Sciences approved the study protocol (research project number: 87115). Provenance and peer review Not commissioned; externally peer reviewed. Data sharing statement № additional data are available.

Open access This is an open access article distributed in accordance with the Creative Commons Attribution Non Commercial (CC BY-NC 4.0) license, which permits others to distribute, remix, adapt, build upon this work non-commercially, and license their derivative works on different terms, provided the original work is properly cited, appropriate credit is given, any changes made indicated, and the use is non-commercial. See: http://creativecommons.org/licenses/by-nc/4.0/.

\section{REFERENCES}

1. Kessler RC, Berglund P, Demler O, et al. Lifetime prevalence and age-of-onset distributions of DSM-IV disorders in the National Comorbidity Survey Replication. Arch Gen Psychiatry 2005;62:593-602.

2. World Health Organization (WHO). Mental disorders. WHO 2016.

3. Noorbala AA, Bagheri Yazdi SA, Hafezi M. Trends in change of mental health status in the population of Tehran between 1998 and 2007. Arch Iran Med 2012;15:201-4.

4. Ahmadvand A, Sepehrmanesh Z, Ghoreishi FS, et al. Prevalence of psychiatric disorders in the general population of Kashan, Iran. Arch Iran Med 2012;15:205-9.

5. Maharlouei N, Hoseinzadeh A, Ghaedsharaf E, et al. The mental health status and associated factors affecting underprivileged Iranian women. Asian J Psychiatr 2014;12:108-12.

6. Caspi A, Sugden K, Moffitt TE, et al. Influence of life stress on depression: moderation by a polymorphism in the 5-HTT gene. Science2003;301:386-9.

7. Heim C, Binder EB. Current research trends in early life stress and depression: review of human studies on sensitive periods, gene-environment interactions, and epigenetics. Exp Neurol 2012;233:102-11.

8. Jacka FN, Mykletun A, Berk M, et al. The association between habitual diet quality and the common mental disorders in community-dwelling adults: the Hordaland Health study. Psychosom Med 2011;73:483-90.

9. Le Port A, Gueguen A, Kesse-Guyot E, et al. Association between dietary patterns and depressive symptoms over time: a 10-year follow-up study of the GAZEL cohort. PLoS One 2012;7:e51593.

10. Sánchez-Villegas A, Verberne L, De Irala J, et al. Dietary fat intake and the risk of depression: the SUN Project. PLOS One 2011;6:e16268.

11. Appleton KM, Peters TJ, Hayward RC, et al. Depressed mood and $n-3$ polyunsaturated fatty acid intake from fish: non-linea or confounded association? Soc Psychiatry Psychiatr Epidemiol 2007;42:100-4

12. Timonen $\mathrm{M}$, Horrobin $\mathrm{D}$, Jokelainen J, et al. Fish consumption and depression: the Northern Finland 1966 birth cohort study. J Affect Disord 2004;82:447-52.

13. Calon F. Omega-3 polyunsaturated fatty acids in Alzheimer's disease: key questions and partial answers. Curr Alzheimer Res 2011;8:470-8.

14. Murakami K, Miyake $Y$, Sasaki S, et al. Dietary folate, riboflavin, vitamin B-6, and vitamin B-12 and depressive symptoms in early adolescence: the Ryukyus Child Health Study. Psychosom Med 2010;72:763-8.

15. Jacka FN, Pasco JA, Mykletun A, et al. Association of Western and traditional diets with depression and anxiety in women. Am J Psychiatry 2010;167:305-11.
16. Kim TH, Choi JY, Lee HH, et al. Associations between Dietary Pattern and Depression in Korean Adolescent Girls. J Pediatr Adolesc Gynecol 2015;28:533-7.

17. Akbaraly TN, Brunner EJ, Ferrie JE, et al. Dietary pattern and depressive symptoms in middle age. $\mathrm{Br} J$ Psychiatry 2009;195:408-13.

18. Hosseinzadeh M, Vafa M, Esmaillzadeh A, et al. Empirically derived dietary patterns in relation to psychological disorders. Public Health Nutr 2016;19:204-17.

19. Motohashi K, Kaneko Y, Fujita K, et al. Interest in dietary pattern, social capital, and psychological distress: a cross-sectional study in a rural Japanese community. BMC Public Health 2013;13:933.

20. Weng TT, Hao JH, Qian QW, et al. Is there any relationship between dietary patterns and depression and anxiety in Chinese adolescents? Public Health Nutr 2012;15:673-82.

21. Lubke $\mathrm{GH}$, Muthén $\mathrm{B}$. Investigating population heterogeneity with factor mixture models. Psychol Methods 2005;10:21-39.

22. Forman-Hoffman VL, Batts KR, Hedden SL, et al. Comorbid menta disorders among adults in the mental health surveillance survey. Ann Epidemiol. In Press. 2018:28:468-74.

23. Montazeri A, Harirchi AM, Shariati M, et al. The 12-item General Health Questionnaire (GHQ-12): translation and validation study of the Iranian version. Health Qual Life Outcomes 2003;1:66.

24. Goldberg D, Williams P. Williams P. A user's guide to the General Health Questionnaire. NferNelson 1988.

25. Zigmond AS, Snaith RP. The hospital anxiety and depression scale. Acta Psychiatr Scand 1983;67:361-70.

26. Montazeri A, Vahdaninia M, Ebrahimi M, et al. The Hospital Anxiety and Depression Scale (HADS): translation and validation study of the Iranian version. Health Qual Life Outcomes 2003;1:14.

27. Mohammadifard N, Sajiadi F, Maghroun M, et al. Validation of a simplified food frequency questionnaire for the assessment of dietary habits in Iranian adults: Isfahan Healthy Heart Program, Iran. ARYA Atheroscler 2015;11:139-46.

28. Kelishadi R, Rabiei K, Khosravi A, et al. Assessment of physical activity of adolescents in Isfahan. Shahrekord University of Medical Sciences Journal 2001;3:55-66.

29. Yadegarfar G, Alinia T, Hassannezhad R, et al. Validation and localization of farsi version of effort-reward imbalance questionnaire to measure job stress among employees of Isfahan polyacryle corporation. Iranian J of Epidemiology 2012;8:73-83.

30. Varriale R, Vermunt JK. Multilevel mixture factor models. Multivariate Behav Res 2012;47:247-75.

31. Stansfeld S, Candy B. Psychosocial work environment and mental health-a meta-analytic review. Scand J Work Environ Health 2006;32:443-62.

32. Henderson M, Harvey SB, Overland S, et al. Work and common psychiatric disorders. J R Soc Med 2011;104:198-207.

33. Farhud DD. Impact of Lifestyle on Health. Iran J Public Health 2015;44:1442-4.

34. Zunszain PA, Hepgul N, Pariante CM. Inflammation and depression. Curr Top Behav Neurosci 2013;14:135-51.

35. $\mathrm{Ng} \mathrm{F}$, Berk M, Dean O, et al. Oxidative stress in psychiatric disorders: evidence base and therapeutic implications. Int $J$ Neuropsychopharmacol 2008;11:851-76.

36. Murakami K, Sasaki S. Dietary intake and depressive symptoms: a systematic review of observational studies. Mol Nutr Food Res 2010:54:471-88

37. Selhub J, Bagley LC, Miller J, et al. B vitamins, homocysteine, and neurocognitive function in the elderly. Am J Clin Nutr 2000;71:614S-20.

38. Lucas M, Chocano-Bedoya P, Schulze MB, et al. Inflammatory dietary pattern and risk of depression among women. Brain Behav Immun 2014:36:46-53.

39. Béchaux C, Zetlaoui M, Tressou J, et al. Identification of pesticide mixtures and connection between combined exposure and diet. Food Chem Toxicol 2013:59:191-8. 